\title{
ПОНЯТИЯ «КОРРУПЦИЯ» И «АДМИНИСТРАТИВНО-ПРАВОВЫЕ МЕРЫ ПРОТИВОДЕЙСТВИЯ КОРРУПЦИИ» В РОССИЙСКОЙ ПРАВОВОЙ ДОКТРИНЕ И ЗАКОНОДАТЕЛЬСТВЕ
}

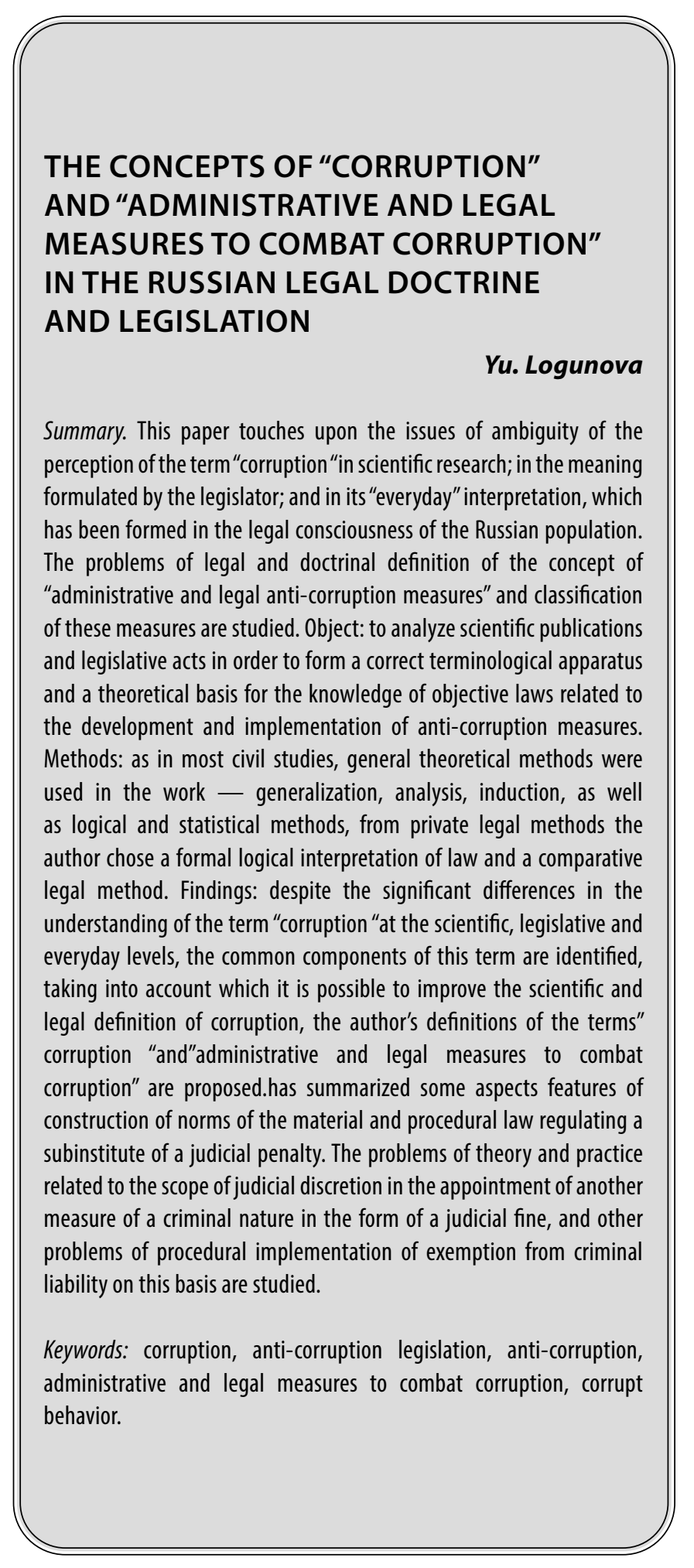

Логунова Юлия Владимировна

Аспирант, Северо-Западный институт управления Российской Академии народного хозяйства и государственной службы при Президенте РФ,

г. Санкт-Петербург

lexterra@list.ru

Аннотация. В статье затронуты вопросы неоднозначности восприятия термина «коррупция» в научных исследованиях; в значении, сформулированном законодателем; и в его «бытовой» интерпретации, которая сформировалась в правосознании населения России. Изучаются проблемы легального и доктринального определения понятия «административно-правовые меры противодействия коррупции» и классификации этих мер. Цель: провести анализ научных публикаций и законодательных актов для формирования корректного терминологического аппарата и теоретической основы для познания объективных закономерностей, связанных с выработкой и реализацией мер по противодействию коррупции. Методы: как и в большинстве цивилистических исследований в работе использовались общетеоретические методы - обобщение, анализ, индукция, а также логический и статистический методы, из частноправовых методов автором были выбраны формально-логическое толкование права и сравнительно правовой метод. Результаты: несмотря на значительное расхождения понимания термина «коррупция» на научном, законодательном и бытовом уровнях, выделены общие компоненты данного термина, с учётом которых возможно совершенствование научного и легального определения коррупции, предложены авторские определения терминов «коррупция» и «административно-правовые меры противодействия коррупции».

Ключевые слова: коррупция, антикоррупционное законодательство, противодействие коррупции, административно-правовые меры противодействия коррупции, коррупционное поведение. 


\section{Ввемение}

$\mathbf{K}$ оррупция как специфическое социальное явление существует в любом обществе, стара, как человечество, проявляется в самых разных формах и, по мнению большинства экспертов, занимающихся данной проблемой, искоренить ее полностью невозможно. Новые сообщения о коррупционных делах появляются почти ежедневно как в российских, так и зарубежных средствах массовой информации. Таким образом, можно уверенно утверждать, что проблема коррупции является актуальной для всех: для развивающихся страны с переходной экономикой, для страны, в которых экономические системы контролируются государством, для промышленно развитых стран со сформированной рыночной экономикой, государств с давними демократическими традициями и государств с авторитарными режимами.

В настоящее время термин о наличии коррупции в каждом из существующих ныне государств не оспаривается, однако можно говорить о низком или высоком уровне коррумпированности. Согласно данным «Индекса восприятия коррупции» (ИВК - ежегодный составной индекс, измеряющий уровень восприятия коррупции в государственном секторе различных стран), российское государство в рейтинге последние годы стабильно занимает низкие места. Например, в 2012 году Россия набрала 28 баллов и заняла 133 место из 176 возможных, в 2013-28 баллов и 127 место из 177, в 2014-27 баллов и 136 место из 172, в 2015-29 баллов и 119 место из 168, в 2018-28 баллов и 138 место из 180, в 2019-28 баллов и 137 место, в 2020-30 баллов и 129 место. Такое положение России в рейтинге означает некоторую нерешительность власти в преследовании коррупционных проявлений, и, следовательно, непродуманность и неэффективность антикоррупционных мероприятий.

Хотя ситуация в Росси в плане борьбы с коррупционными проявлениями, пусть медленно, но изменяется к лучшему, общественное мнение продолжает считать Россию высоко коррумпированной страной. Негативное влияние на борьбу с коррупцией в России оказывает отсутствие корректного законодательного определения термина «коррупция», что приводит к отсутствия единства понимания рассматриваемого явления на юридическом и бытовом планах, а также коллизионности правовых норм, регулирующих административно-правовые меры по противодействию коррупции.

В связи с этим, формирование корректного терминологического аппарата приобретает характер одной из важнейших межотраслевых, междисциплинарных, научных и практических задач, поскольку именно ка- тегориальный инструментарий юридической науки формирует требуемую в современных условиях теоретическую основу для познания объективных закономерностей, связанных с выработкой и реализацией мер по противодействию коррупционным проявлениям.

В рамках статьи предпримем попытку провести анализ понятий «коррупция» и «административно-правовые мер противодействия коррупции», что позволит выявить проблемных моменты их трактовки и наметить пути решения спорных моментов.

\section{Материалы и метолы}

В ходе работы над статьей проводился анализ доступных статистических и информационных данных, опубликованных на официальных сайтах Верховного Суда РФ, Генеральной прокуратуры РФ, Минюста РФ, антикоррупционной общественной организации Transparency International, осмысление научных исследований, посвященных проблематике борьбы с коррупцией, изучение российских нормативно-правовых актов. Исследование базируется на диалектическом методе, использовались также теоретические методы исследования: обобщение, анализ, индукция, логический и статистический методы, и частнонаучные - формально-логическое толкование права и сравнительно правовой метод.

\section{Результаты и обсужАение}

Как совершенно справедливо отмечает О.В. Барабаш, коррупция, как многоаспектное явление, в течении столетий становился предметом анализа и научного осмысления с позиций «правовой, политической, обыденной коммуникации», что привело к выстраиванию понятия коррупции как концепта - «системы знаний, оценок, ассоциаций», а также ментальных установок, которые ложатся в основу восприятия обществом определенных деяний как коррупционных [1, с. 223]. Несмотря на длительность изучения феномена коррупции с социальных, экономических, политических, лингвистических, правовых и философских ракурсов, современное научное сообщество не пришло к единству относительно сущности коррупции. Активный научный диспут продолжается относительно объема легальной дефиниции термина «коррупция».

Безусловно, неоднозначность восприятия термина «коррупция» обусловлена не только многоуровневостью данного явления, требующего междисциплинарного подхода для его осмысления, но и все более проявляющимся, расхождением понимания термина «коррупция» в научных исследованиях в рамках отдельных дисциплин и отраслей знания; в значении, 
сформулированном законодателем; и в той «бытовой» его интерпретации, которая закрепляется в правосознании общества.

Обращаясь к этимологии слова «коррупция», отметим, что латинское существительное «corruptus» означает «разорение, порча, разврат», латинский глагол «corrumpere» трактуется как «повреждать, портить, подделывать, уничтожать, приводить в упадок, губить, развращать, растлевать, искажать», а в богословии латинское слово «correptio» использовалось при описании первородного греха с позиции испорченности человеческой природы, обозначая врожденную порочность, недостаток добра и склонность к злу [2].

Проанализировав изложенные в публикациях О.В. Барабаш, К.Б. Филиппова, В.М. Быкова, О.В. Дамаскина, Н.А. Лопашенко, А.И. Долговой, О.В. Назарова, Г.К Мишина, Ю.П. Синельщикова, Ю.А. Тихомирова, П.А. Кабанова, Ю.Г. Наумова, Л.Н. Колодкина, М.В. Клиомовой, Л.Д. Гаухмана, Е.Е. Новичковой и ряда других авторов подходы к интерпретации термина «коррупция» в его правовом контексте можно отметить, что несмотря на значительную разницу во взглядах исследователей, имеется и ряд общих характеристик коррупции как социально-правового явления:

л любая форма коррупции представляет собой нарушение доверия как явление, в котором личный интерес ставится выше интересов общего блага;

- это активное осознанное поведение, которое отклоняется от формальных обязательств общественной роли (на которую человек был избран или назначен) с целью получения имущественных либо неимущественных преимуществ как личного, так и группового (кланового, корпоративного) характера;

- это злоупотребление властью, предоставленной лицу в силу специфики занимаемой им должности, для получения им частной прибыли, которое происходит в ситуации тайного обмена «вознаграждениями» ${ }^{1}$ между двумя или более сторонами;

- это явление тесно связано с нравственным восприятием ценностей человеком, а также спецификой делового этикета, сформированного в определённом обществе - один и тот же вопрос можно рассматривать под разными углами, как нормальное деловое поведение или как коррупционное проявление;

- в более ранних исследований коррупция неразрывно связывалась с государственным сектором,

\footnotetext{
' В данном случае одна из сторон (лицо, обладающее статусом) получает имущество, деньги, ценности или услуги, а другая - требуемое ей преимущество.
}

однако постепенно научное сообщество расширяет границы восприятия данного явления, отмечая, что нет ни одного социального института, который не был бы поражен ею, следовательно, и в частной сфере коррупция должна законодательно пресекаться, так как она подрывает саму идею честной конкуренции.

Следует отметить, что дискуссионным остается вопрос о разграничении коррупции на ситуационную (ситуативную) и системную. Ситуативному коррупционному акту не предшествует целевое планирование или подготовка. Скорее, спонтанное волевое решение приводит к единовременному незаконному действию, подпадающему под действие соответствующих статей УК РФ или КоАП РФ. Дело разовое, повторение не планируется. В случае системной коррупции предполагается намеренно спланированное действие, основанное на долгосрочных коррупционных отношениях и определенная степень их организованности. Она носит крупномасштабный характер, может быть организована как на национальном, так и на международном уровне, смыкаясь с организованной преступностью. Полагаем, что для очерчивания границ дефиниции «коррупция» и определения тех компонент, которые позволят разграничить коррупцию от иных противоправных действий, следует определить коррупцию как системное явление. В случае единичного ситуативного акта его корректнее трактовать не как коррупцию, но как отдельное преступление, административное правонарушение, либо дисциплинарный проступок (например, взятка, хищение, и проч). Из этого не следует, что единичное правонарушение безобидно - угроза для общества очевидна, поскольку каждое такое деяние готовит почву для системной коррупции.

Таким образом, в настоящее время в юридических и смежных исследованиях коррупция трактуется достаточно широко как аморальный противоправный обмен выгодами и преимуществами, базирующийся на злоупотреблении доверенной властью для удовлетворения личных (частных) интересов. Указанный обмен представляет собой сделку между акторами, аморальность и противоправность которой обусловлена тем, что в коррупционном акте человек платит за то, что на самом деле не должно продаваться, приводя к конфликту между частными и общественными интересами. Исходя из этого, следует отметить, что коррупция - это двусторонний акт с определенной взаимностью, поскольку в коррупционном деянии всегда помимо лица, облеченного властью и злоупотребляющего ей в частно-корыстных интересах, участвует и тот, кто заинтересован в подобном поведении властного субъекта. Причем коррупционное поведение предполагает как незаконное, так и законное использование должност- 
ных обязанностей, но оно всегда аморально, поскольку стремление личной выгоды перевешивает необходимость блюсти общественные интерес. Иллюстрацией данного положения может являться пример, приведенный в публикации Барабаш О.В. и Филиппова К.Б. где анализируется ситуация, «при которой государственный регистратор, получив взятку, осуществляет регистрацию сделки с недвижимостью, скажем, уже на второй день из пятнадцати установленных законом дней», т.е. действует формально не выходя за рамки законного использования полномочий, но в частных интересах и получения личной выгоды [3, с. 16].

Следует отметить, что единого общепринятого определения коррупции в российской правовой доктрине не выработано. На международном уровне концепция коррупции также подвергается критическому анализу: попытки четко отграничить коррупцию от других форм социально отклоняющегося поведения не слишком удачны, однако достигнуты и определенные положительные результаты - не оспаривается, что коррупционную преступность не следует рассматривать лишь в национальном масштабе, исследования не должны зависеть от того, как отдельное государство относится к определенному социально-девиантному поведению с точки зрения внутренней правовой политики, признается, что чистая ориентация на уголовные нормы не соответствует имеющемуся в реальности разнообразии видов и форм коррупционного поведения, и соответственно сведение коррупции к уголовным преступлениям приведет к ограничению правового инструментария противодействия коррупции.

Коррупцию часто приравнивают к взяточничеству, поэтому отправной точкой для попыток легального определения, реализованных в Федеральном законе «О противодействии коррупции» от 25.12.2008 № 273Ф3 (далее - Ф3 «О коррупции»), является открытый перечень деяний, которых законодатель посчитал коррупционным: злоупотребление служебным положением; дача взятки; получение взятки; злоупотребление полномочиями; коммерческий подкуп; иное незаконное использование физическим лицом своего должностного положения вопреки законным интересам общества и государства в целях получения имущественной выгоды для себя или третьих лиц. В научной литературе данная дефиниция подвергается обоснованной и активной критике. Отмечается, в частности, что набор отдельных случаев коррупционного поведения, типологизированных в двух группах (первая содержит закрытый перечень уголовно-правовых деяний, вторая - неконкретизированный объем коррупционных деликтов) делает термин «коррупция» расплывчатым, стирая грань между социально полезным и социально вредным поведением [4, с. 107]; ограничение выгоды только имущественным характером, выводит значительную долю коррупционных проявлений, таких как лоббизм, протекционизм, кумовство, семейственность, попустительство и проч., из сферы действия антикоррупционного законодательства [3, с. 17,18; 4, с. 108]; использование конструкции «иное незаконное использование ...должностного положения» не отражает современные реалии, когда коррупционные деяния физического лица могут иметь формально законный характер [3, с. 16; 5, с. 47]; некорректность использования понятий «служебное положение» и «должностное положение» нарушает требования законодательной техники [5, с. 46]. Таким образом, законодательная дефиниция коррупции требует доработки.

Бытовое понимание коррупции двояко. Большинство населения коррупцию на нижнем уровне власти воспринимают коррупцию как неизбежного условие беспрепятственного прохождение в инстанциях интересующего их вопроса и получение необходимого им конкретного решения государственного органа. Более того, справедливо осуждая коррупцию как в целом аморальное явление, они одновременно рассматривают ее как жизненную реалию, распространенное социально-приемлемое поведение, терпимое отношение к которому обусловлено преимуществами, получаемыми в ходе коррупционных актов обеими сторонами, а также пониманием, что в ряде повседневных ситуаций убытки от принципиальности несоизмеримо выше оплаты действий коррупционера.

На высшем уровне власти бытовое трактование термина «коррупция» используется для недифференцированной популистской критики власти в рамках высказываний типа: «они все там коррумпированы», а также для осуждения инструментализации политической борьбы за власть.

Таким образом, несмотря на то, что термин «коррупция» широко используется в различных областях научного знаний, нормативно-правовых актах и на бытовом уровне, его смысловое наполнение весьма различается в зависимости от уровня восприятия (научный, законодательный, бытовой), а легальная дефиниция требует доработки.

Вопросы эффективного и качественного противодействия коррупции, которая наносит значительный экономический ущерб, а также ущерб репутации государства и бизнеса, ставит под сомнение порядочность и авторитет власти, безусловно, очень актуальны и зависят не только от понимания коррупции в конкретном обществе, но и от системы мер, которые государство разрабатывает для предотвращения и борьбы с данным явлением. 
Противодействие коррупции в Ф3 «О коррупции» определено как деятельность федеральных и региональных органов власти, органов местного самоуправления, институтов гражданского общества, организаций и физических лиц по трем направлениям: профилактика коррупции, борьба с коррупцией, и минимизация и (или) ликвидации последствий коррупционных правонарушений.

Однако кодифицированного нормативного акта федерального уровня, содержащего перечень мер противодействия коррупции, а также определяющего их сущностное наполнение, российский законодатель не выработал. Само понятие «меры противодействия коррупции» легального определения не имеет и разрабатывается, как и классификация этих мер, юридической наукой, в частности в трудах С.Н. Братановского, М.Ф. Зеленова, А.В. Полукарова, В.А. Вовк и других авторов.

Отметим, что упоминание о мерах противодействия коррупции содержится в ст. 6 Ф3 «О коррупции» (меры по профилактике), в Указе Президента РФ от 19.05.2008 № 815 (ред. от 17.05.2021) «О мерах по противодействию коррупции» (однако наименование указа не в полной мере отвечает содержанию документа, поскольку в нем речь идет о структуре и задачах Совет при Президенте Российской Федерации по противодействию коррупции), в актах регионального уровня, к примеру в Законе г. Москвы от 17.12.2014 № 64 «О мерах по противодействию коррупции в городе Москве», Законе Санкт-Петербурга от 14.11.2008 № 674-122 «О дополнительных мерах по противодействию коррупции в Санкт-Петербурге» и иных аналогичных законах субъектов РФ.

Анализ научных публикаций и законодательных актов позволяет сделать выводы о том, что: (1) система мер противодействия коррупции развивается по двум направлениям - уголовно-правовое и административно-правовое; (2) хотя законодатель использует термин «меры» ряд автором предлагают заменить его на термин «средства»; (3) перечень административно-правовых мер различен, однако большинство авторов и нормативных источников отмечают в качестве основных такие меры как: антикоррупционная экспертиза нормативных правовых актов; антикоррупционный мониторинг; антикоррупционная пропаганда и просвещение; антикоррупционные ограничения, запреты и обязанности; антикоррупционные требования к служебному поведению, планирование антикоррупционной стратегии; (4) ни легального, ни доктринального определения понятия «административно-правовые меры противодействия коррупции» в настоящее время не выработаHo.

\section{Зак^ючение}

Проведённое исследование позволяет сделать следующие выводы и предложения по дальнейшему направлению исследований в рассматриваемой области:

1. Приняв во внимание международный опыт и российскую практику возможно ввести в научный оборот следующее определение коррупции. Коррупция - это двусторонний акт с определенной степенью взаимности, заключающийся в системном использовании должностными лицами, государственными и муниципальными служащими, представителями управленческого персонала коммерческих и некоммерческих организаций и иными лицами своего служебного положения или статуса с одной стороны, и физических либо юридических лиц, обратившихся для удовлетворения своих интересов к субъекту, обладающему властным статусом с другой, в целях незаконного извлечения личных, групповых либо корпоративных выгод (преимуществ) имущественного и неимущественного характера, вопреки законным интересам других лиц, общества и государства. Вне зависимости от того, какой из сторон принадлежит инициатива в коррупционном акте, коррупционное поведение предполагает взаимность, в данном контексте рассматриваемую нами как добровольность выбранного противоправного поведения, поскольку у обеих сторон имеется возможность обратиться за помощью в правоохранительные органы в случае принуждения либо склонения к коррупционному акту.

2. Учеными-правоведами легальная дефиниция «коррупции» подвергается обоснованной и активной критике. Представляется обоснованной позиция С.Н. Братановского и М.Ф. Зеленова, акцентировавших внимание на том факте, что в отечественной юридической науке данное понятие формировалось преимущественно в рамках теории уголовного права, однако сформулированное законодателем определение не привело к правовой определенности по данному вопросу, напротив, содержит многочисленные неточности, противоречит некоторым положениям УК РФ и неоправданно сужает круг коррупционных проявлений [6]. Полагаем, что дальнейшее направление исследований лежит в области осмысления целесообразности введения легальной дефиниции «коррупция» в российское правовое поле в принципе, а в случае решения данного вопроса положительно, доработка понятия может включать введение следующих характеристик коррупции: (1) злоупотребление служебным положением в механизме государственного управ- 
ления, политике или бизнесе, позволяющим принимать решения или, по крайней мере, влиять на их принятие; (2) коррупционный акт - это акт сотрудничества как минимум между лицом, обладающим статусом и третьей стороной; (3) получение (стремление к получению) частной выгоды (для себя или третьих лиц) либо преимущества; (4) деятельность вопреки правомерным интересам других лиц, общества и государства; (5) с секретностью / сокрытием этих действий.
3. Под административно-правовыми мерами противодействия коррупции следует понимать законодательно установленную систему элементов воздействия на общественные отношения, складывающиеся в сфере государственного и муниципального управления, с целью профилактики коррупции, борьбы с коррупционными правонарушениями и проступками, а также минимизация и (или) ликвидации последствий коррупционных правонарушений и проступков.

\section{ЛИТЕРАТУРА}

1. Барабаш 0.В. Концепт «коррупция» и его репрезентации в семантическом пространстве русского языка // Политическая лингвистика. 2017 . № 6. C. 223-229.

2. Дыдынский Ф.М. Латинско-русский словарь к источникам римского права / 2-е изд., испр. и доп. Варшава: тип. К. Ковалевского, 1896. 466 с.

3. Барабаш 0.В., Филиппов К.Б. «Коррупция» как ключевое понятие антикоррупционного законодательства Российской Федерации: лингво-правовой анализ дефиниции // Политическая лингвистика. 2014. № 4. С. 14-20.

4. Будатаров С.М. Понятие коррупции в российском законодательстве и юридической литературе // Вестн. Том. гос. ун-та. 2012. № 359. С. 106-110.

5. Ищук Я.Г. Коррупция: вопросы теоретического осмысления // Академическая мысль. 2018. № 1 (2). С. 45-50.

6. Братановский С.Н., Зеленов М.Ф. Административно-правовые аспекты борьбы с коррупцией в системе исполнительной власти в РФ: монография. М.: Проспект, 2018. 256c.

(c) Логунова Юлия Владимировна ( lexterra@list.ru).

Журнал «Современная наука: актуальные проблемы теории и практики»

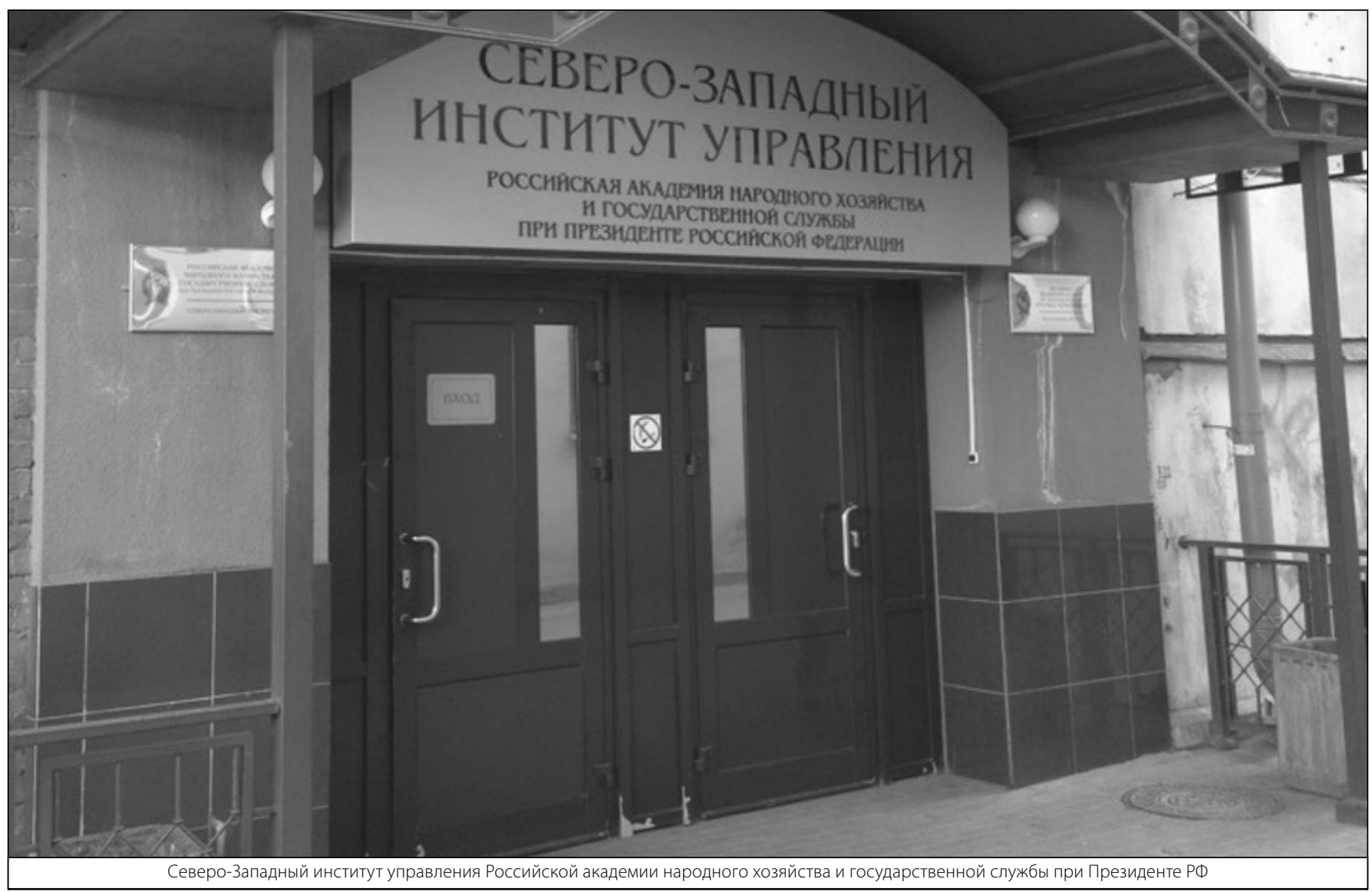

